\title{
MONITORING OF GENE EXPRESSION IN DIFFERENTIATION OF EMBRYOID BODIES FROM CYNOMOLGUS MONKEY EMBRYONIC STEM CELLS IN THE PRESENCE OF BISPHENOL A
}

\author{
Megumi YAMAMOTO ${ }^{1,2}$, Naomi TASE ${ }^{3}$, Tsuyoshi $\mathrm{OKUNO}^{4}$, Yasushi $\mathrm{KONDO}^{4}$, \\ Suminori AKIBA ${ }^{5}$, Nobuhiro SHIMOZAWA ${ }^{3}$ and Keiji TERAO ${ }^{3}$ \\ ${ }^{1}$ Physiology Section, Department of Basic Medical Sciences, National Institute for Minamata Disease, \\ 4058-18 Hama, Minamata, Kumamoto 867-0008, Japan \\ ${ }^{2}$ Environmental Health Sciences Division, National Institute for Environmental Studies, \\ 16-2 Onogawa, Tsukuba, Ibaraki 305-8506, Japan \\ ${ }^{3}$ Tsukuba Primate Research Center, National Institute of Biomedical Innovation, \\ 1-1 Hachimandai, Tsukuba, Ibaraki 305-0843, Japan \\ ${ }^{4}$ Advanced Medical Research Laboratories, Tanabe Seiyaku Co., Ltd., \\ 3-16-89 Kashima, Yodogawa-ku, Osaka 532-8505, Japan \\ ${ }^{5}$ Department of Epidemiology and Preventive Medicine, \\ Kagoshima University Graduate School of Medical and Dental Sciences \\ 8-35-1 Sakuragaoka, Kagoshima 890-8544, Japan
}

(Received April 24, 2007; Accepted May 8, 2007)

\begin{abstract}
An embryonic stem (ES) cell differentiation model would facilitate analysis of developmental processes at the cellular level and the effects of embryotoxic and teratogenic factors in vitro. We explored the use of differentiation of embryoid bodies (EBs) from cynomolgus monkey ES cells for embryotoxicity testing. We determined the mRNA expression of various genes using real-time RT-PCR. Oct-3/4 expression was almost completely suppressed on day 14, suggesting that ES cells reached differentiated status in around 14 days. mRNA expression of E-cadherin, connexin 43, caveolin-1, and argininosuccinate synthetase was reproducibly suppressed during EB differentiation in 7-32\% of ES cells in three separate experiments. Although these may not be "general stemness marker genes" such as Oct-3/ 4 , they could play a role in readying stem cells for differentiation in response to deletion of signals from feeder cells. Next, we examined the effects of bisphenol A (BPA) on the mRNA expression of several differentiation marker genes for ES cells. That of PAX-6, an ectoderm marker, with 0, 0.1, and $10 \mu \mathrm{M}$ BPA in 21-day EBs was 3,500\%, 6,668\%, and 8,394\%, respectively, compared with ES cells. The difference between doses of 0 and $10 \mu \mathrm{M}$ BPA in 21-day EBs was statistically significant ( $\mathrm{p}=0.049)$. Pax-6 activation in the presence of BPA may interfere with the development of eyes, sensory organs, and certain neural and epidermal tissues usually derived from ectodermal tissues. Differentiation of EBs from cynomolgus monkey ES cells could be a useful model for detecting gene expression changes in response to chemical exposure.
\end{abstract}

KEY WORDS: Embryonic stem cell, Embryoid body, Differentiation, Monkey, Bisphenol A, Embryotoxicity

\section{INTRODUCTION}

Embryonic stem (ES) cells have great potential for cell therapy and regenerative medicine, but also represent a dynamic system suitable for identifying potential molecular targets for the development of novel

Correspondence: Megumi YAMAMOTO (E-mail: yamamoto@nimd.go.jp) 
drugs, providing an in vitro system to examine safety or potential toxicity in humans (Davila et al., 2004; Wobus and Boheler, 2005). Particularly promising is the ES cell differentiation model, which includes developmental processes from early embryonic stages up to terminally differentiated cell types and which would enable us to analyze developmental processes at the cellular level and to determine the effects of embryotoxic and teratogenic factors in vitro. Establishing a reliable in vitro embryogenesis model would also contribute to a reduction in the number of animal experiments required for medical and pharmacological testing.

Experimental studies using non-human primate ES cells have advantages such as similar characteristics to human ES cells that are not observed in murine ES cells, and avoidance of the ethical problems caused by the use of human ES cells (Thomson et al., 1995; Suemori and Nakatsuji, 2003; Adachi et al., 2006; Byrne et al., 2006). To date, however, the ES cell test for testing embryotoxicity primarily uses murine ES cells (Spielmann et al., 1997; Scholz et al., 1999; Imai and Nakamura, 2006). As a result, our knowledge on the molecular and cellular aspects of ES cells for embryotoxicity testing is based mainly on murine cells, and information on non-human primate ES cells is limited.

In the course of ES cell differentiation, genes encoding tissue-specific proteins are expressed in a developmentally controlled time pattern that closely resembles what is observed during embryogenesis. ES cells differentiate in vitro into embryoid bodies (EBs) comprising endoderm, mesoderm and ectoderm cell layers in the absence of the self-renewal signals provided by feeder layers (Weitzer, 2006). EB formation is considered to mimic embryo development during the stages of pre-gastrulation and early gastrulation. Using a mouse EB model, Wartenberg et al. examined antiangiogenic agents in an in vitro assay system (Wartenberg et al., 1998). However, to our knowledge, little information is available on the primate EB differentiation model for embryotoxicity screening.

Bisphenol A (BPA) is commonly used in various industries. Its monomer is used for polycarbonate plastic production, and its resin form is used as linings for most food and beverage cans, as dental sealant, and as an additive in other widely used consumer products. BPA is known to elicit weak estrogenic activity in in vitro and in vivo test systems. Although molecular mechanisms studies have revealed a variety of pathways in which BPA can stimulate cellular responses at very low doses in addition to the effects initiated by its binding to the classical estrogen receptors, there is little information available concerning the effect of BPA on early embryogenesis (vom Saal and Hughes, 2005; Kang et al., 2006).

In the present study, to develop a model system for primate embryotoxicity testing, we used BPA as a model compound and examined changes of gene expression in response to exposure to BPA using cynomolgus monkey EB differentiation. We conducted experiments in three steps. Firstly, we determined the time necessary for EB differentiation in cynomolgus monkey ES cells, examining the expression of Oct-3/4, a POU-class transcription factor. This stemness marker gene was used since loss of pluripotency during spontaneous or induced differentiation has been correlated with progressive loss of Oct-3/4 expression (Niwa, 2001; Mitalipov et al., 2003). In addition to morphological changes, we determined mRNA expression levels using real-time RT-PCR. This quantitative approach is rapid and sensitive and is considered suitable for pharmacological and cytotoxicity screening. Monitoring of ES cell differentiation with quantitative PCR has recently been reported (Noaksson et al., 2005). Secondly, we examined the expression of several genes whose proteins were highly expressed in ES cells compared with EBs. These genes were selected on the basis of preliminary results obtained from a comparison of the protein-expression profiles of various genes in 1216-day-old CMK-6 ES cells and CMK-6 EBs with Green Fluorescent Protein (Furuya et al., 2003) using Power Blot ${ }^{\mathrm{TM}}$, a Western blot array analysis (unpublished result). In the third step, we examined the effects of BPA on mRNA expression of the following differentiation marker genes for ES cells: $\alpha$-fetoprotein (AFP) and GATA-4 as endoderm markers; BMP-4 and Brachyury as mesoderm markers; and PAX-6 and NCAM as ectoderm markers.

\section{MATERIALS AND METHODS}

\section{Cell culture}

The ES cell lines (CMK-6) used in this study were established from blastocysts of the cynomolgus monkey and were kindly provided by Dr Norio Nakatsuji of Kyoto University (Fig. 1A; Suemori et al., 2001).

ES cells were grown on mouse embryonic fibroblast (MEF) feeder cells that were mitotically inactivated by mitomycin C in Dulbecco's Modified Eagle's Medium (DMEM/F12) (SIGMA) supplemented with 
Gene expression with bisphenol A in monkey embryoid body differentiation.

$20 \%$ knock-out serum replacement (Invitrogen), 1\% non-essential amino acids (SIGMA) and $2 \mathrm{mM} \mathrm{L-}$ glutamine (SIGMA) at $37^{\circ} \mathrm{C}$ in a humidified $5 \% \mathrm{CO}_{2}$ atmosphere.

For EB differentiation, entire ES cells colonies were loosely detached by $0.1 \%(\mathrm{w} / \mathrm{v})$ collagenase (Wako Pure Chemical) from the feeder cells and transferred into a feeder-free $25 \mathrm{~cm}^{2}$ flask (SUMILON) for floating culture. The medium was changed after the first day and half of it was changed every 7 days.

EBs $\left(2 \times 10^{5} / \mathrm{ml}\right)$ were incubated for 7,14 or 21 days with $0.1 \mu \mathrm{M}$ or $10 \mu \mathrm{M}$ BPA (SIGMA). In the control group, the same volume of DMSO was added to the media. Stock BPA (100 mM) was dissolved in DMSO and was stored at $-20^{\circ} \mathrm{C}$. The BPA was further diluted in culture medium just before use, and was sterilized through a filter with a pore size of $0.22 \mu \mathrm{m}$. The final DMSO concentration did not exceed $0.1 \%$ (vol/ vol).

When harvesting ES cells and EBs for mRNA expression analysis, they were washed three times with PBS and then pooled at $-80^{\circ} \mathrm{C}$ until RNA extraction.

\section{Quantitative real-time RT-PCR}

Total RNA from ES cells and EBs was isolated using a RNeasy Plus Mini kit (QIAGEN), which includes removal of genomic DNA contamination before cDNA synthesis. Samples were collected from three separate culture experiments.

cDNAs were synthesized from total RNA ranging from $100 \mathrm{ng}$ to $1 \mu \mathrm{g}$ using QuantiTect Reverse Transcription (QIAGEN) after elimination of genomic DNA contamination.

$\beta$-actin and differentially expressed genes were quantitatively detected with a LightCycler Instrument (Roche Diagnostics) using the LightCycler FastStart
DNA Mater ${ }^{\text {PLUS }}$ SYBR Green I (Roche Diagnostics) according to the manufacturer's instructions.

The primers for each gene were designed and synthesized on the basis of respective information in NCBI or ENSEMBL using the software of Premiere Biosoft, so that the targets were 75-200 bp in length (SIGMA GENOSYS, Table 1).

PCR amplification was performed in a total volume of $20 \mu \mathrm{l}$ containing cDNA and each primer $(0.5$ $\mu \mathrm{M})$. The PCR cycling conditions were $95^{\circ} \mathrm{C}$ for 10 min followed by 45 cycles of $95^{\circ} \mathrm{C}$ for $10 \mathrm{sec}, 60^{\circ} \mathrm{C}$ for $10 \mathrm{sec}$, and $72^{\circ} \mathrm{C}$ for $15 \mathrm{sec}$. The fluorescent product at the end of the $72^{\circ} \mathrm{C}$ extension period was detected. All PCR assays were performed in at least duplicate.

The data obtained were analyzed using the LightCycler analysis software. To confirm the amplification specificity, we subjected the PCR products to melting curve analysis. The results are given as the mean $\pm \mathrm{SE}$ of samples from three separate culture experiments. The statistical analysis was conducted using KruskalWallis test.

\section{RESULTS}

As shown in Fig. 1A and B, cynomolgus monkey ES cells spontaneously differentiated into EBs after separation from the MEFs. Fig. 2 shows the timecourse of mRNA expression of Oct-3/4 in EBs in relation to that on Day 1 (ES cell). The average mRNA expression levels of Oct-3/4 in EBs were 3\%, 0.9\%, and $0.4 \%$ at 7 days, 14 days and 21 days, respectively, compared with ES cells. No significant effect of BPA on Oct-3/4 expression in EB differentiation was observed.

Next, we examined the mRNA expression of genes selected by the preliminary experiments
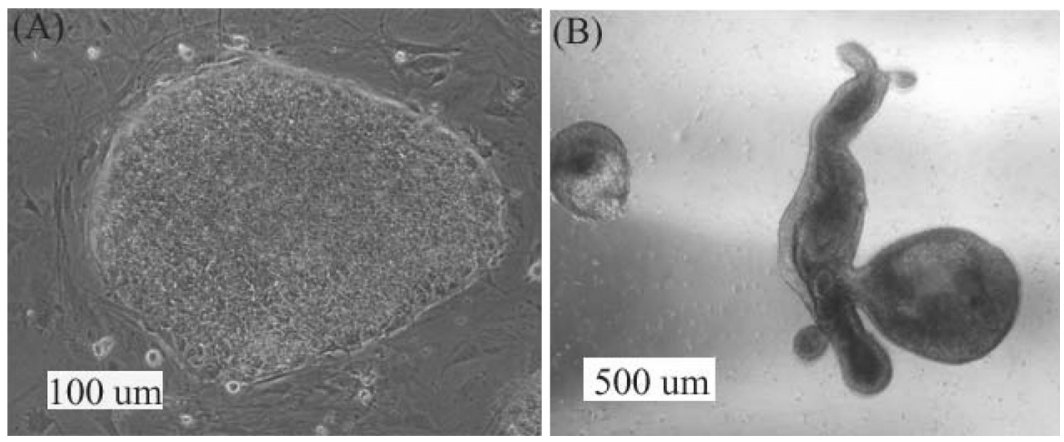

Fig. 1. A: Cynomolgus monkey ES cells, CMK-6.

B: EBs derived from CMK-6 ES cells on Day 14. 
described in the Introduction. E-cadherin, connexin 43, caveolin-1, and ASS were consistently suppressed during EB differentiation. In the absence of BPA, the mRNA expression of E-cadherin was suppressed to

Table 1. Primer sequences for real timeRT-PCR.

\begin{tabular}{|c|c|}
\hline Gene & Primers \\
\hline \multirow[t]{2}{*}{$\beta$-actin } & F: ACCCCGTGCTGCTGACC \\
\hline & R: CCAGAGGCGTACAGGGATAGC \\
\hline \multirow[t]{2}{*}{ Oct-3/4 } & F: GCTCCTGAAGCAGAAGAGGATCACC \\
\hline & R: GCCCTTCTGGCGCCGGTTACAGAAC \\
\hline \multirow[t]{2}{*}{ E-cadherin } & F: AAGACCAAGTGACCACCTTAGAG \\
\hline & R: AAACAGCAAGAGCAGCAGAATC \\
\hline \multirow[t]{2}{*}{ Connexin-43 } & F: TTCAATGGCTGCTCCTCACC \\
\hline & R: GCTCACTTGCTTGCTTGTTGTA \\
\hline \multirow[t]{2}{*}{ Caveolin-1 } & F: CGGCTCAACTCGCATCTCAAG \\
\hline & R: GCCAGGAACACCGTCAGGA \\
\hline \multirow[t]{2}{*}{ ASS } & F: TGGCTGAAGGAACAAGGCTATG \\
\hline & R: GCTGACATCCTCAATGAACACC \\
\hline \multirow[t]{2}{*}{ AFP } & F: AGCTTGGTGGTGGATGAA \\
\hline & R: CAGCCTCAAGTTGTTCCTCT \\
\hline \multirow[t]{2}{*}{ PAX-6 } & F: ACAGACACAGCCCTCACAAAC \\
\hline & R: ATCATAACTCCGCCCATTCACC \\
\hline
\end{tabular}

$12 \%, 20 \%$, and $21 \%$ at 7 days, 14 days and 21 days, respectively, compared with ES cells (Fig. 3A). In the absence of BPA, the mRNA expression of connexin 43 was suppressed to $32 \%, 32 \%$ and $27 \%$ at 7 days, 14 days and 21 days, respectively (Fig. 3B). In the absence of BPA, the mRNA expression of caveolin-1 was suppressed to $17 \%, 26 \%$ and $21 \%$ at 7 days, 14 days and 21 days, respectively (Fig. 3C). In the absence of BPA, the mRNA expression of ASS was suppressed to $10 \%, 9 \%$ and $7 \%$ at 7 days, 14 days and 21 days, respectively (Fig. 3D). There were no detectable differences on microscopy between the BPA treatment and non-treatment groups. In addition, no significant effect of BPA was observed on the expression of these genes in EB differentiation.

In the third step, we examined the effects of BPA on the mRNA expression of the following differentiation marker genes for ES cells: AFP, GATA-4, BMP-4, Brachyury, PAX-6, and N-CAM. The results for two genes, AFP and PAX-6, which gave reproducible results in three separate cultures, are presented in Fig. $4 \mathrm{~A}$ and $\mathrm{B}$. The mean AFP mRNA expression in 14-day EBs was 204,132\% in the presence of $10 \mu \mathrm{M}$ BPA and $130,635 \%$ in the absence of BPA. The difference was

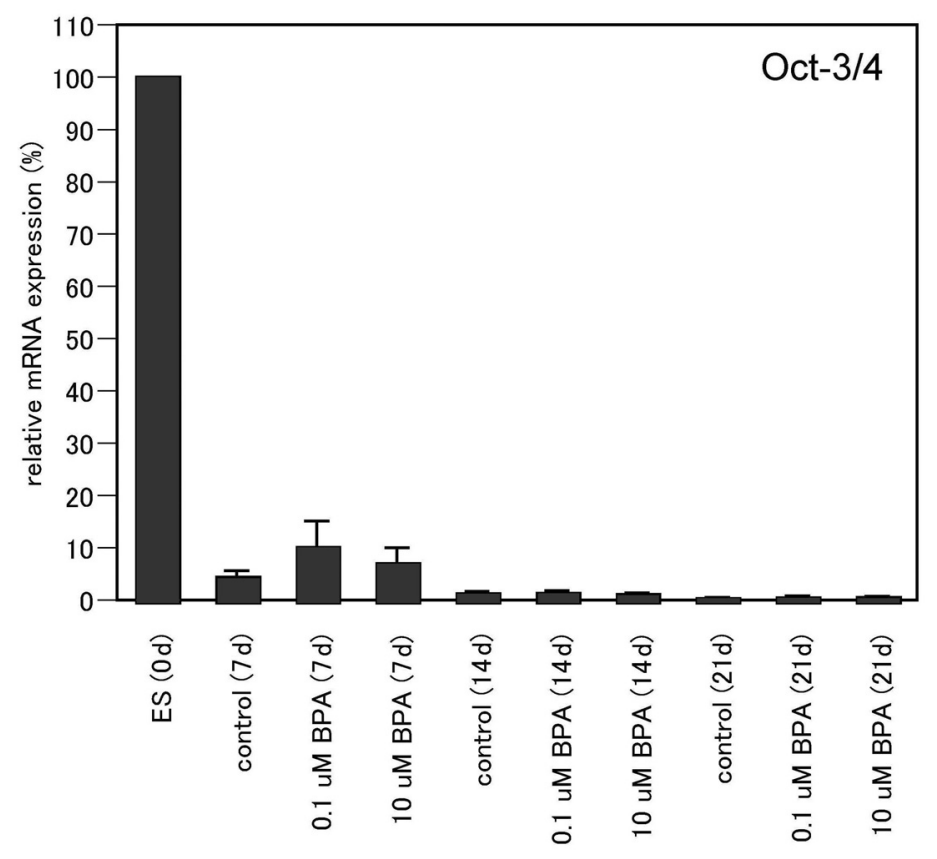

Fig. 2. mRNA expression of Oct-3/4 in EB differentiation at 7, 14 and 21 days. Control: DMSO; $0.1 \mathrm{uM}$ : $0.1 \mu \mathrm{M}$ BPA; $10 \mathrm{uM}: 10 \mu \mathrm{M}$ $\mathrm{BPA}$. Values are mean $\pm \mathrm{SE}$ of three independent experiments. 
Gene expression with bisphenol A in monkey embryoid body differentiation.

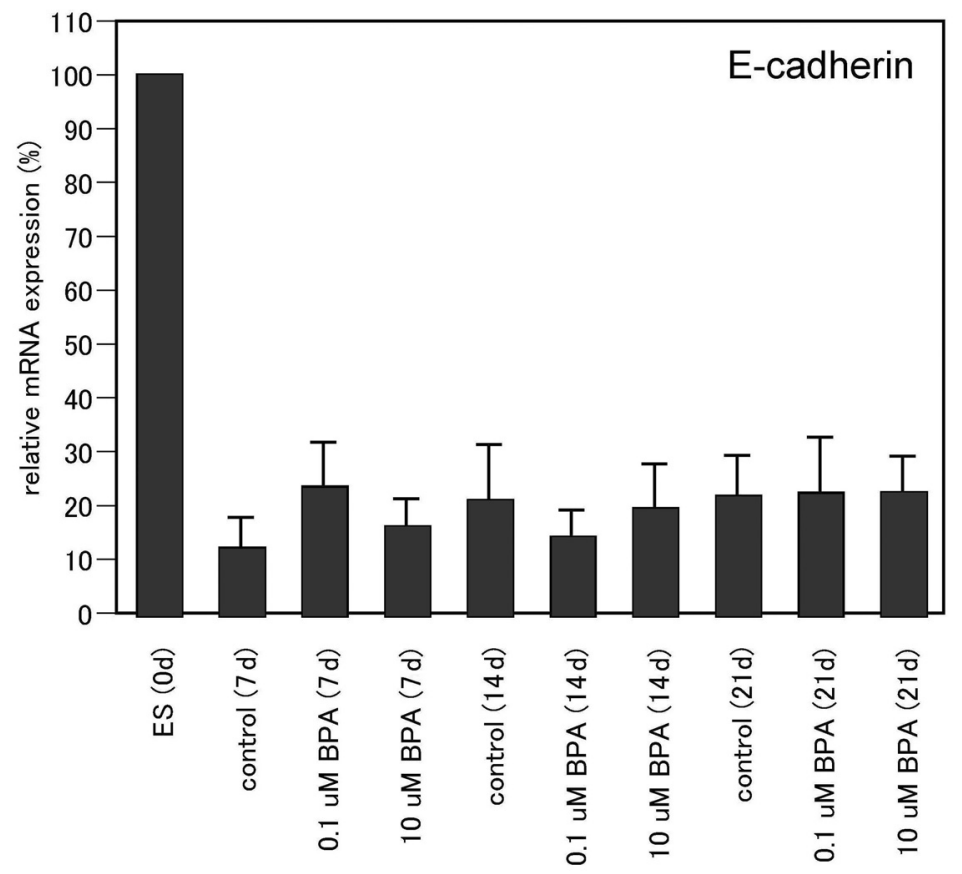

Fig. 3A. mRNA expression of E-cadherin in EB differentiation at 7, 14 and 21 days. Control: DMSO; $0.1 \mathrm{uM}$ : $0.1 \mu \mathrm{M}$ BPA; $10 \mathrm{uM}$ : $10 \mu \mathrm{M}$ $\mathrm{BPA}$. Values are mean $\pm \mathrm{SE}$ of three independent experiments.

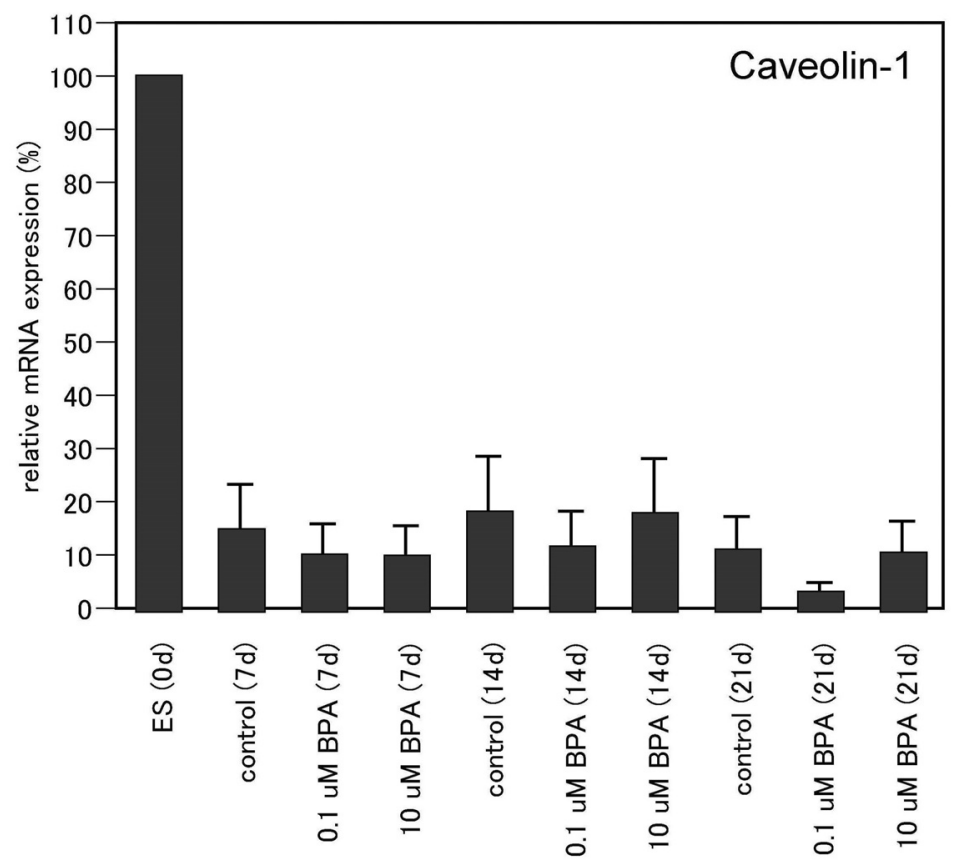

Fig. 3B. mRNA expression of caveolin-1 in EB differentiation at 7, 14 and 21 days. Control: DMSO; $0.1 \mathrm{uM}$ : $0.1 \mu \mathrm{M}$ BPA; $10 \mathrm{uM}$ : $10 \mu \mathrm{M}$ $\mathrm{BPA}$. Values are mean $\pm \mathrm{SE}$ of three independent experiments. 
M. YAMAMOTO et al.

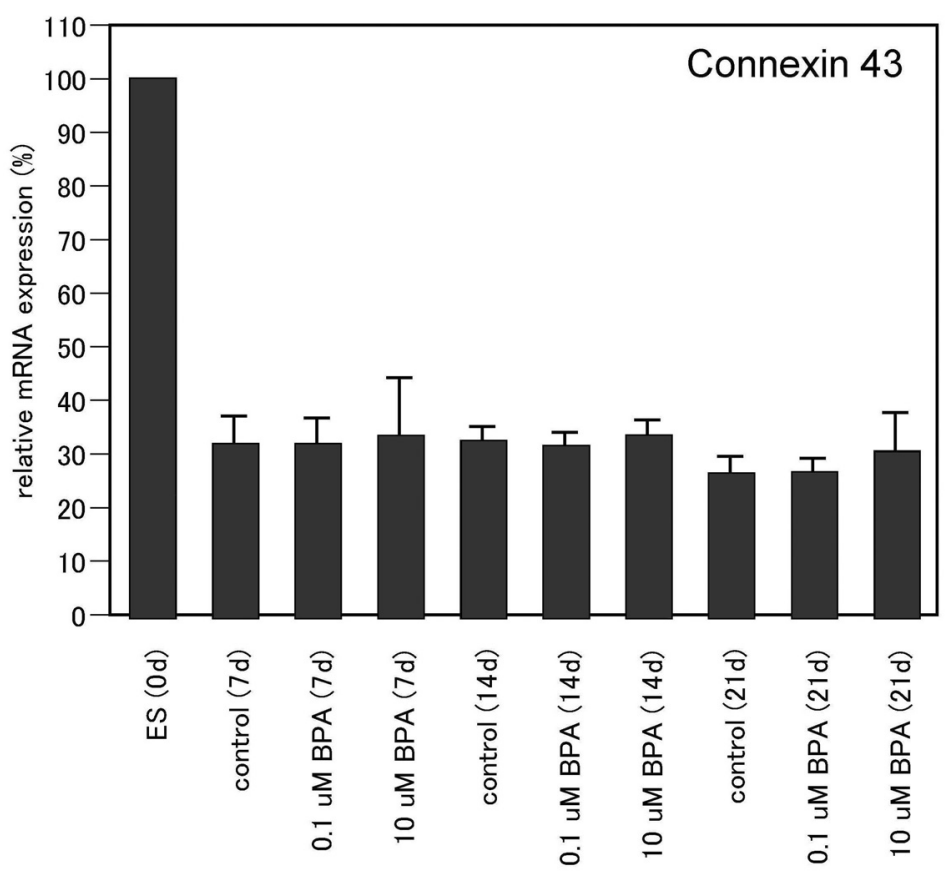

Fig. 3C. mRNA expression of connexin-43 in EB differentiation at 7, 14 and 21 days. Control: DMSO; $0.1 \mathrm{uM}: 0.1 \mu \mathrm{M}$ BPA; $10 \mathrm{uM}: 10$ $\mu \mathrm{M}$ BPA. Values are mean $\pm \mathrm{SE}$ of three independent experiments.

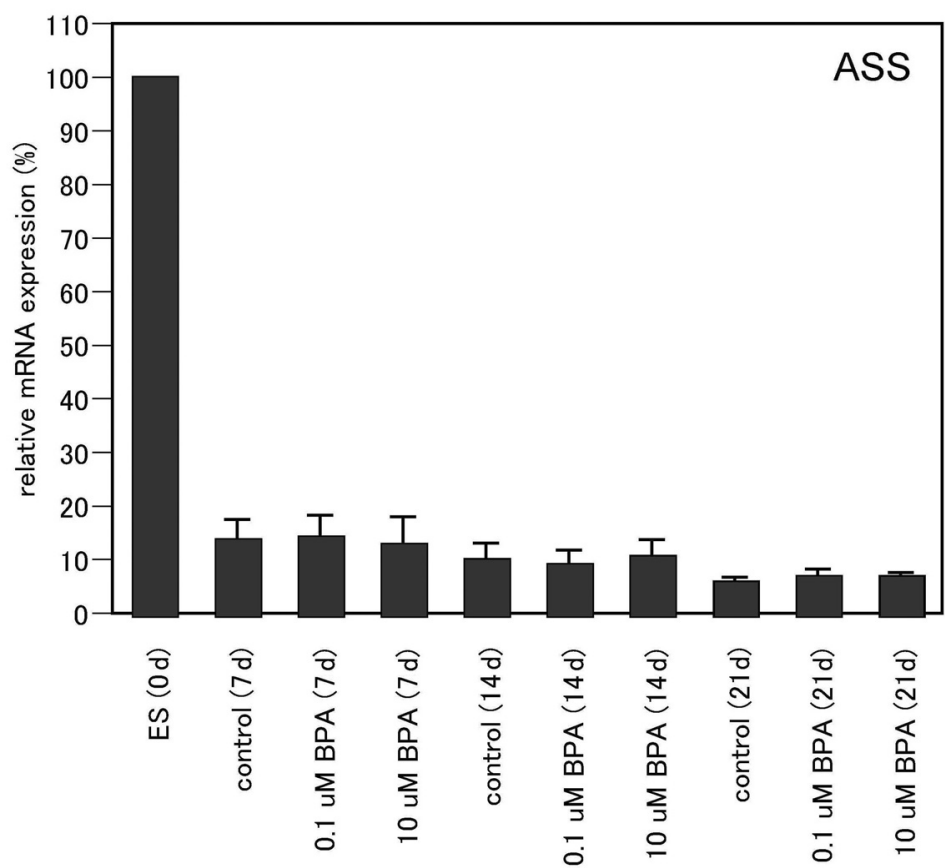

Fig. 3D. mRNA expression of ASS in EB differentiation at 7, 14 and 21 days. Control: DMSO; $0.1 \mathrm{uM}$ : $0.1 \mu \mathrm{M}$ BPA; $10 \mathrm{uM}: 10 \mu \mathrm{M}$ BPA. Values are mean \pm SE of three independent experiments. 
Gene expression with bisphenol A in monkey embryoid body differentiation.

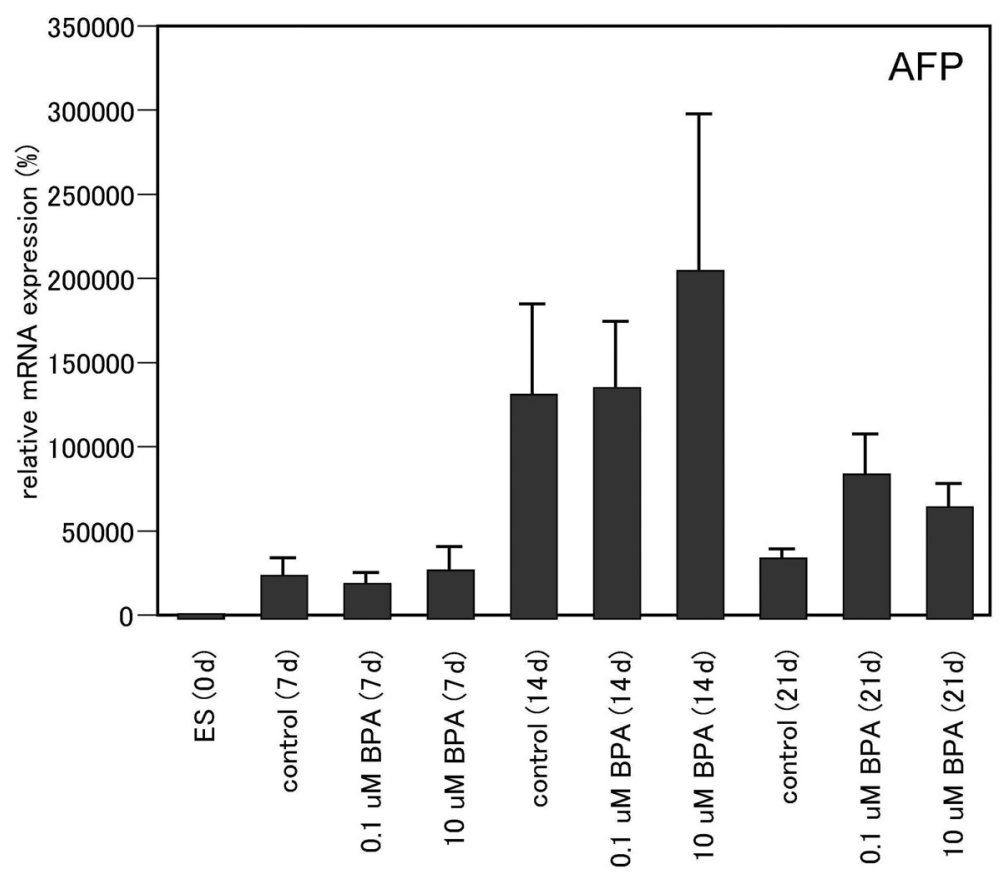

Fig. 4A. Effect of BPA on AFP mRNA expression in EB differentiation at 7, 14 and 21 days. Control: DMSO; $0.1 \mathrm{uM}$ : $0.1 \mu \mathrm{M}$ BPA; $10 \mathrm{uM}: 10$ $\mu \mathrm{M}$ BPA. Values are mean $\pm \mathrm{SE}$ of three independent experiments.

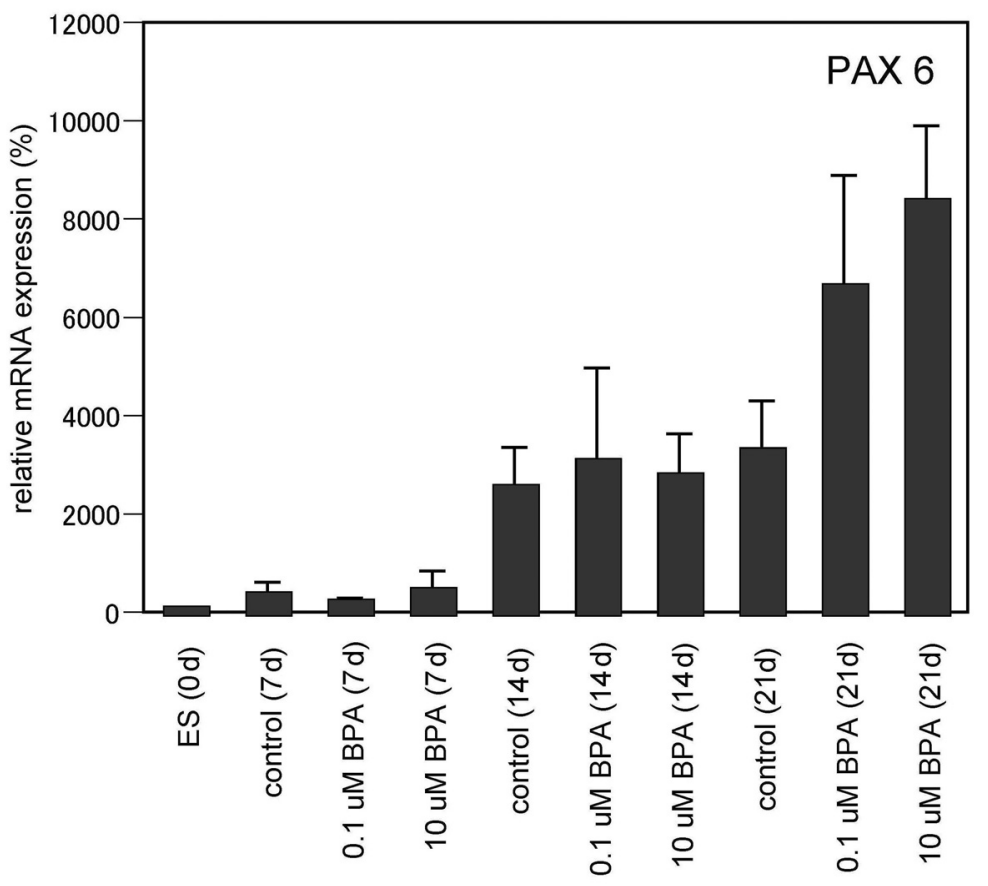

Fig. 4B. Effect of BPA on PAX-6 mRNA expression in EB differentiation at 7, 14 and 21 days. Control: DMSO; $0.1 \mathrm{uM}$ : $0.1 \mu \mathrm{M}$ BPA; $10 \mathrm{uM}: 10$ $\mu \mathrm{M}$ BPA. Values are mean $\pm \mathrm{SE}$ of three independent experiments. 
not statistically significant $(\mathrm{p}=0.513)$. In 21-day EBs, the average mRNA expression in the presence of $0,0.1$ $\mu \mathrm{M}$ and $10 \mu \mathrm{M}$ was $33,418 \%$ (reference category for $\mathrm{p}$ value calculation), $80,100 \%(\mathrm{p}=0.049)$ and $63,787 \%$ $(p=0.049)$ respectively. The averages of three separate experiments of PAX-6 mRNA expression in the presence of $0,0.1$ and $10 \mu \mathrm{M}$ BPA in 21-day EBs were $3,500 \%, 6,668 \%$ and $8,394 \%$, respectively, compared with ES cells. The difference between doses of 0 and $10 \mu \mathrm{M}$ was statistically significant $(\mathrm{p}=0.049)$. The difference between doses of 0 and $0.1 \mu \mathrm{M}$ was not statistically significant $(\mathrm{p}=0.275)$. On Days 7 and 14, BPA did not show any evident effects on PAX-6 mRNA expression.

\section{DISCUSSION}

mRNA expression of Oct-3/4 was almost completely suppressed on Day 14, suggesting that ES cells reached differentiated status in around 14 days. E-cadherin, connexin 43, caveolin-1 and ASS were also consistently suppressed during EB differentiation (Table 2 ). The time patterns of their mRNA expression were similar to that of Oct-3/4. The cadherins are a class of transmembrane proteins that play important roles in cell adhesion. E-cadherin is first expressed in the 2-cell stage of mammalian development, and becomes phosphorylated in the 8-cell stage, where it causes compaction (Halbleib and Nelson, 2006). Connexin 43 is known to be related to gap junction-related protein, and gap junctions play significant regulatory roles in embryonic development (King and Lampe, 2005). Caveolin-1 has been shown to be the structural protein of plasmalemmal invaginations, termed caveolae, and functions as a tumor suppressor gene (Sotgia et al., 2006). The tyrosine-phosphorylated form of caveolin1 co-localizes with focal adhesions, suggesting that caveolin-1 plays a role in migration. Down-regulation of caveolin-1 leads to less efficient migration in vitro. ASS is an enzyme that catalyzes argininosuccinate synthesis from citrulline and aspartate, and is responsi-

Table 2. Average of mRNA expression of undifferentiated stem cell state-related genes.

\begin{tabular}{|l|c|c|c|c|}
\hline & $1 \mathrm{~d}-\mathrm{ES}$ & $7 \mathrm{~d}-\mathrm{EB}$ & $14 \mathrm{~d}-\mathrm{EB}$ & $21 \mathrm{~d}-\mathrm{EB}$ \\
\hline Oct-3/4 & $100 \%$ & $3 \%$ & $0.9 \%$ & $0.4 \%$ \\
\hline E-cadherin & $100 \%$ & $12 \%$ & $20 \%$ & $21 \%$ \\
\hline Connexin 43 & $100 \%$ & $32 \%$ & $32 \%$ & $27 \%$ \\
\hline Caveolin-1 & $100 \%$ & $17 \%$ & $26 \%$ & $21 \%$ \\
\hline ASS & $100 \%$ & $10 \%$ & $9 \%$ & $7 \%$ \\
\hline
\end{tabular}

ble for the third step of the urea cycle and one of the reactions of the citrulline-NO cycle (Husson et al., 2003). ASS is highly conserved from bacteria to humans, and is present in large amounts in many tissues, including liver and kidney. It is difficult to discuss the significance of down-regulation of E-cadherin, connexin 43, caveolin-1, and ASS during EB differentiation, because they were selected by their ES/EB ratio in protein expression profiling. They may not be "general stemness marker genes" such as Oct-3/4, expression of which is always suppressed in any type of differentiation. However, they at least play a role, not only in maintaining the undifferentiated stem cell state, but also in readying stem cells for EB differentiation in response to deletion of signals from the MEFs. Reproducible results in some genes were obtained in separate experiments, indicating that this EB differentiation system could work as an embryotoxicity test.

In response to BPA, expression of AFP andPAX6 was increased at least temporarily. AFP is a glycoprotein that is produced principally in the fetal liver and gastrointestinal tract and is temporarily present during embryonic development. Estrogens were reported to modify AFP, exhibiting growth-suppressive properties (Vakharia and Mizejewski, 2000). BPA may interfere with the interaction between AFP and estrogen in EB differentiation. Recently, non-estrogenic effects of BPA on the central nervous system have been reported. In mice, prenatal and neonatal exposure to BPA induces a significant increase in the levels of dopamine $D_{1}$ receptor $m R N A$ in the brain and increases central dopamine $\mathrm{D}_{1}$ receptor-mediated activity (Suzuki et al., 2003). In addition, expression of PAX-6 mRNA in embryos of Xenopus laevis was reported to be suppressed by treatment with 50 or 100 $\mu \mathrm{M}$ BPA from stage 10.5 to stage 35 (Imaoka et al., 2007). PAX-6 is recognized as a master control gene for the development of eyes, sensory organs and certain neural and epidermal tissues that are usually derived from ectodermal tissues (Kondoh et al., 2004). BPA may be related to one of the above functions in early development. The reason why the mRNA expression results for some genes were not reproducible may be that inappropriate primers were used for RT-PCR, that transfection with GFP may alter the characteristics of cells or that changes due to BPA may have occurred at the translational level rather than the transcriptional level.

In conclusion, our results indicated that this EB differentiation from cynomolgus monkey ES cells could work for detecting changes of gene expression in 
Gene expression with bisphenol A in monkey embryoid body differentiation.

response to BPA exposure, and could contribute to developing a primate ES embryotoxicity test in the near future.

\section{ACKNOWLEDGMENT}

The authors are grateful to Dr Colin R. Jefcoate (University of Wisconsin-Madison, USA), Dr Seishiro Hirano (National Institute for Environmental Studies), Dr Kunihiko Nakamura (National Institute for Minamata Disease) and Dr Koji Arizono (Prefectural University of Kumamoto) for their valuable comments, and to Ms Tomoyo Aratake and Ms Kiyoko Iwatsubo (National Institute for Minamata Disease) for their assistance in preparing the manuscript. This study was partly supported by a Grant (No. H16- REGENERATION-002) from the Ministry of Health, Labour, and Welfare of Japan.

\section{REFERENCES}

Adachi, K., Kawase, E., Yasuchika, K., Sumi, T., Nakatsuji, N. and Suemori, H. (2006): Establishment of the gene-inducible system in primate embryonic stem cell lines. Stem Cells, 24, 2566-2572.

Byrne, J.A., Mitalipov, S.M., Clepper, L. and Wolf, D.P. (2006): Transcriptional profiling of rhesus monkey embryonic stem cells. Biol. Reprod., 75, 908-915.

Davila, J.C., Cezar, G.G., Thiede, M., Strom, S., Miki, T. and Trosko, J. (2004): Use and application of stem cells in toxicology. Toxicol. Sci., 79, 214223.

Furuya, M., Yasuchika, K., Mizutani, K., Yoshimura, Y., Nakatsuji, N. and Suemori, H. (2003): Electroporation of cynomolgus monkey embryonic stem cells. Genesis, 37, 180-187.

Halbleib, J.M. and Nelson, W.J. (2006): Cadherins in development: Cell adhesion, sorting, and tissue morphogenesis. Gene Dev., 20, 3199-3214.

Husson, A., Brasse-Lagnel, C., Fairand, A., Renouf, S. and Lavoinne, A. (2003): Argininosuccinate synthetase from the urea cycle to the citrullineNO cycle. Eur. J. Biochem., 270, 1887-1899.

Imai, K. and Nakamura, M. (2006): In vitro embryotoxicity testing of metals for dental use by differentiation of embryonic stem cell test. Congenit Anom., 46, 34-38.

Imaoka, S., Mori, T. and Kinoshita, T. (2007): Bisphenol A causes malformation of the head region in embryos of Xenopus laevis and decreases the expression of the ESR-1 gene mediated by Notch signaling. Biol. Pharm. Bull., 30, 371374.

Kang, J.H., Kondo, F. and Katayama, Y. (2006): Human exposure to bisphenol A. Toxicology, 226, 79-89.

King, T.J. and Lampe, P.D. (2005): Temporal regulation of connexin phosphorylation in embryonic and adult tissues. Biochim. Biophys. Acta, 1719, 24-35.

Kondoh, H., Uchikawa, M. and Kamachi, Y. (2004): Interplay of Pax 6 and SOX2 in lens development as a paradigm of genetic switch mechanisms for cell differentiation. Int. J. Dev. Biol., 48, 819-827.

Mitalipov, S.M., Kuo, H.C., Hennebold, J.D. and Wolf, D.P. (2003): Oct-4 expression in pluripotent cells of the rhesus monkey. Biol. Reprod., 69, 1785-1792.

Niwa, H. (2001): Molecular mechanism to maintain stem cell renewal of ES cells. Cell Struct. Funct., 26, 137-148.

Noaksson, K., Zoric, N., Zeng, X., Rao, M.S., Hyllner, J., Semb, H., Kubista, M. and Sartipy, P. (2005): Monitoring differentiation of human embryonic stem cells using real-time PCR. Stem Cells, 23, 1460-1467.

Scholz, G., Pohl, I., Genschow, E., Klemm, M. and Spielmann, H. (1999): Embryotoxicity screening using embryonic stem cells in vitro: Correlation to in vivo teratogenicity. Cells Tissues Organs, 165, 203-211.

Sotgia, F., Rui, H., Bonuccelli, G., Mercier, I., Pestell, R.G. and Lisanti, M.P. (2006): Caveolin-1, mammary stem cells, and estrogen-dependent breast cancers. Cancer Res., 66, 10647-10651.

Spielmann, H., Pohl, I., Doering, B., Liebsch, M. and Moldenhauer, F. (1997): The embryonic stem cell test, an in vitro embryotoxicity test of two permanent mouse cell lines: $3 \mathrm{t} 3$ fibroblasts and embryonic stem cells. In Vitro Toxicol., 10, 199-207.

Suemori, H., Tada, T., Torii, R., Hosoi, Y., Kobayashi, K., Imahie, H., Kondo, Y., Iritani, A. and Nakatsuji, N. (2001): Establishment of embryonic stem cell lines from cynomolgus monkey blastocysts produced by IVF or ICSI. Dev. Dynam., 222, 273-279.

Suemori, H. and Nakatsuji, N. (2003): Growth and differentiation of cynomolgus monkey ES cells. 
Method Enzymol., 365, 419-429.

Suzuki, T., Mizuo, K., Nakazawa, H., Funae, Y., Fushiki, S., Fukushima, S., Shirai, T. and Narita, M. (2003): Prenatal and neonatal exposure to bisphenol-A enhances the central dopamine D1 receptor-mediated action in mice: Enhancement of the methamphetamine-induced abuse state. Neuroscience, 117, 639-644.

Thomson, J.A., Kalishman, J., Golos, T.G., Durning, M., Harris, C.P., Becker, R.A. and Hearn, J.P. (1995): Isolation of a primate embryonic stem cell line. P. Natl. Acad. Sci. U. S. A., 92, 78447848.

Vakharia, D. and Mizejewski, G.J. (2000): Human alpha-fetoprotein peptides bind estrogen receptor and estradiol, and suppress breast cancer. Breast Cancer Res. Tr., 63, 41-52. vom Saal, F.S. and Hughes, C. (2005): An extensive new literature concerning low-dose effects of bisphenol A shows the need for a new risk assessment. Environ. Health Persp., 113, 926933.

Wartenberg, M., Gunther, J., Hescheler, J. and Sauer, H. (1998): The embryoid body as a novel in vitro assay system for antiangiogenic agents. Lab. Invest., 78, 1301-1314.

Weitzer, G. (2006): Embryonic stem cell-derived embryoid bodies: An in vitro model of eutherian pregastrulation development and early gastrulation. Handb. Exp. Pharmacol., 174, 21-51.

Wobus, A.M. and Boheler, K.R. (2005): Embryonic stem cells: Prospects for developmental biology and cell therapy. Physiol. Rev., 85, 635-678. 